\title{
A Simulation-Based LED Design Project in Photonics Instruction Based on Industry-University Collaboration
}

\author{
Shu-Hsuan Chang, Mei-Ling Chen, Yen-Kuang Kuo, and Yung-Chi Shen
}

\begin{abstract}
In response to the growing industrial demand for light-emitting diode (LED) design professionals, based on industry-university collaboration in Taiwan, this paper develops a novel instructional approach: a simulation-based learning course with peer assessment to develop students' professional skills in LED design as required by industry as well as to enhance cognition and metacognition in students in higher education. The simulation-based learning course enables students to understand the influences on LED performance of the variation of different parameters and to seek the best design through comparing the effectiveness of different combinations of parameters. The evaluation results of pre- and post-test knowledge maps and a photonics scoreboard indicate that this project-based instruction may help students understand the operating principles of LEDs and enhance their skill in LED design. The Constructivist Project-based Learning Environment Survey is adopted to demonstrate that the proposed project-based learning environment is beneficial in cultivating student inquiry learning, reflective thinking, teamwork, and skills in creative problem solving.
\end{abstract}

Index Terms-Light-emitting diode (LED), peer assessment (PA), project-based learning (PBL), simulation-based learning (SBL).

\section{INTRODUCTION}

$\mathbf{L}$ IGHT-EMITTING diodes (LEDs) are devices made from semiconductor materials that convert electric energy into light through recombination of electrons and holes. The application scope of LEDs has widened recently. LEDs are mainly applied to instruments that need a point or planar light source, such as electronic products, home appliances, automobiles, traffic signals, and signboards. Taiwan has gained the second largest market share in the global LED market since 2002 [1]. According to the 2009 LEDinside Report, Taiwan's market size for

Manuscript received May 14, 2010; revised July 22, 2010; accepted November 15, 2010. Date of publication January 06, 2011; date of current version November 02, 2011. This work was supported in part by the National Science Council (NSC) of Taiwan under Grants NSC 95-2516-S-018-001-MY3 and NSC 98-2511-S-018-006-MY3.

S.-H. Chang is with the Department of Industrial Education and Technology, National Changhua University of Education, Taiwan (e-mail: shc@cc.ncue.edu. tw).

M.-L. Chen is with the Department of Physics, National Changhua University of Education, Changhua, Taiwan.

Y.-K. Kuo is with the Department of Physics and Institute of Photonics, National Changhua University of Education, Changhua, Taiwan.

Y.-C. Shen is with the Graduate Institute of Technology Management, National Chiao-Tung University, Taiwan.

Color versions of one or more of the figures in this paper are available online at http://ieeexplore.ieee.org.

Digital Object Identifier 10.1109/TE.2010.2098877

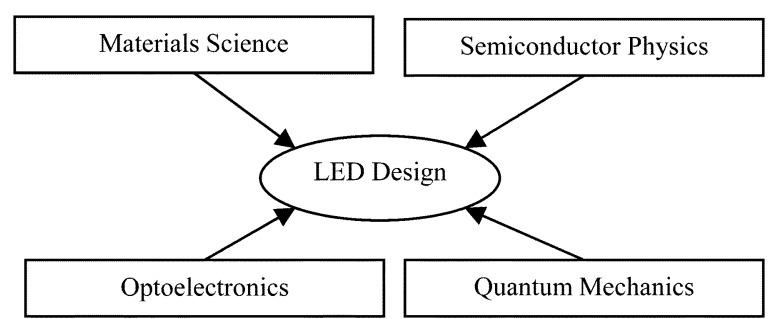

Fig. 1. Required prior knowledge for LED design.

LEDs will be NT \$540 billion in 2015 [2]. Efficiently fostering LED design professionals has become an issue in higher education so as to satisfy the growing need for workers in Taiwan's LED industry.

The production of optical semiconductor devices requires repeated iterations of the steps of design, crystal growth, and test to achieve the desired performance, which can be very time-consuming and expensive. If the optimized design can be achieved by using simulation software before the start of mass production, the time and cost required for the development of the devices can be markedly reduced by the elimination of unnecessary trial fabrications. Therefore, some companies in Taiwan have adopted the following procedures for research and development. First, the structure and characteristics of a preliminary LED prototype, or an LED whose detailed structure and characteristics have been published in a journal, are duplicated and simulated. Second, optimal design is attempted by adjusting the design parameters to achieve the desired characteristics. Finally, the resulting higher-performance LEDs can be fabricated for mass production. An industry-university collaboration model has been developed in such a way that the university partner carries out the first and second of these steps to develop an optimal or satisfactory device design, and then the industry partner company implements the device design to fabricate the products [3].

For a student in higher education to successfully complete an LED design requires prior knowledge of semiconductor physics, quantum mechanics, optoelectronics, and material science, as shown in Fig. 1. Universities need to offer an interdisciplinary curriculum that combines theory and practice to engage students in authentic real-world tasks [4] and to develop their skills in creative problem solving [5].

Problem-oriented and project-based learning (POPBL) is a learning approach that integrates and applies knowledge in realworld tasks for technical as well as nontechnical fields [4], [6]. Project-based learning (PBL) starts with an assignment to undertake one or more tasks, which might be to create a model, 
a device, or a computer simulation [5]. The learning process adopts a question or problem that guides students to design the study process, solve problems, make decisions, and conduct research. Students autonomously engage in relevant work to complete a real product and to present their research results when the assignment is completed [4], [7], [8]. Students develop not only their knowledge of and skills in the given study subjects, but also their abilities in self-regulated learning [9], teamwork, and dealing with interdisciplinary issues [10], [11].

Simulation-based learning (SBL) is intended to imitate realworld phenomena to prepare students for future industrial practice [12]. It helps students to understand the real world, be able to explore and test hypotheses, and come to a reasoned explanation of the phenomenon in question [13]. Therefore, computer simulation has been adopted in an increasing number of fields in engineering education, including electronics, automotive power systems, induction motors, and photonics instrumentation [14]-[17]. However, SBL has some limitations. Some investigations have found that while students master the operation of computer simulation software, they do not properly understand the subject concepts [18], [19]. Additionally, some studies have revealed that the simulation itself cannot provide an abundant learning environment and that one-on-one simulation-based instruction cannot enrich knowledge acquisition [20]. In general, it is still a challenge to integrate course design and instruction with computer simulation so as to enhance students' cognition and metacognition in higher education.

In order to avoid the aforementioned problems, this paper develops a novel instruction approach from the viewpoint of constructivism. The philosophical concepts of constructivism emphasize the importance of meaningful, authentic activities that help the learners construct understandings and develop skills relevant to solving problems [21]. Although there may be many forms of constructivism, the constructivists generally assert that knowledge is actively constructed by individuals and that social interactions with others also play an important role in the construction process [22]-[25]. The designers of constructivist learning environments adopt seven pedagogical goals [26], [27]: 1) to provide experience with the knowledge construction process; 2) to provide experience in and appreciation for multiple perspectives; 3) to embed learning in realistic and relevant contexts; 4) to encourage ownership and voice in the learning process (i.e., student-centeredness); 5) to embed learning in social experience; 6) to encourage the use of multiple modes of representation; and 7) to encourage self-awareness of the knowledge construction process (i.e., an extension of meta-cognitive and reflective activities).

Topping [28] claims that through a peer assessment (PA) learning activity, learners' thinking skills may be enhanced. Online PA (Internet-assisted PA) has been a success [29], providing a more comfortable learning environment that is free from geographic and time constraints and that allows participants to work and be graded anonymously. Its active computer-supported collaborative learning environment promotes critical thinking, planning, monitoring, and regulation [30].

Based on the industry-university collaboration in Taiwan, the work presented here adopts the aforementioned seven goals of constructivist learning environments as design prin- ciples to develop a SBL course with online PA. The goals are to enhance students' professional skills in LED design as required by industry and to enhance their cognition and metacognition. Knowledge maps, a photonics scoreboard, and the Constructivist Project-based Learning Environment Survey (CPLES) [31] were conducted to demonstrate the success of this learning course.

\section{Procedure of the Project-BASed Course}

The objectives of the project-based course were: 1) to understand the theoretical and practical concepts of LED design engineering; 2) to obtain hands-on experience of LED design during the course project using APSYS computer simulation software; and 3) to enhance metacognition of engineering students in higher education. To perform the simulation successfully, students must thoroughly learn the subject material.

This study involved a one-term project designed for an experimental physics class for junior students in the Department of Physics, National Changhua University of Education, Taiwan, where the material science module is run in the sophomore year of the curriculum. The semiconductor physics, optoelectronics, and quantum mechanics modules are run in the junior or senior year. Therefore, students had to acquire this knowledge that they had yet to be taught through teamwork, online PA, and computer simulation - the distinct features of this course. They had to try to clarify their concepts and complete the LED design with limited prior knowledge. The instructor and the teaching assistant were simply facilitators in the class.

Fig. 2 gives the procedure for the project-based course. The steps of the procedure and their design concept are explained as follows.

Step 1) The instructor explained the objective and syllabus of the course and the LED design project, including the knowledge map and the simulation software. Moreover, the professor introduced and explained basic LED knowledge, including the basic structure of an LED and its operating principle, LED materials, the emission spectrum, the structure of quantum wells, internal quantum efficiency, spontaneous emission, and the factors affecting LED performance.

Step 2) Students were grouped into heterogeneous teams according to their grades in the sophomore year. Each group was requested to select one industrial LED application, such as displays or traffic signals, as the topic of a case study and to research the relevant information to provide a verbal report discussing the operating principle of an LED and the factors affecting its performance. The aim of this report was to stimulate students to learn for themselves the operating principle of LEDs and other fundamental knowledge. In this step, the instructor and teaching assistant discussed the students' reports with them.

Step 3) The third step was the pretest of the study, in which students' concepts were surveyed at the LED design stage by a knowledge map pretest before they started the two-stage simulation.

Step 4) This step involved project implementation with the two-stage simulation. The first stage of LED 


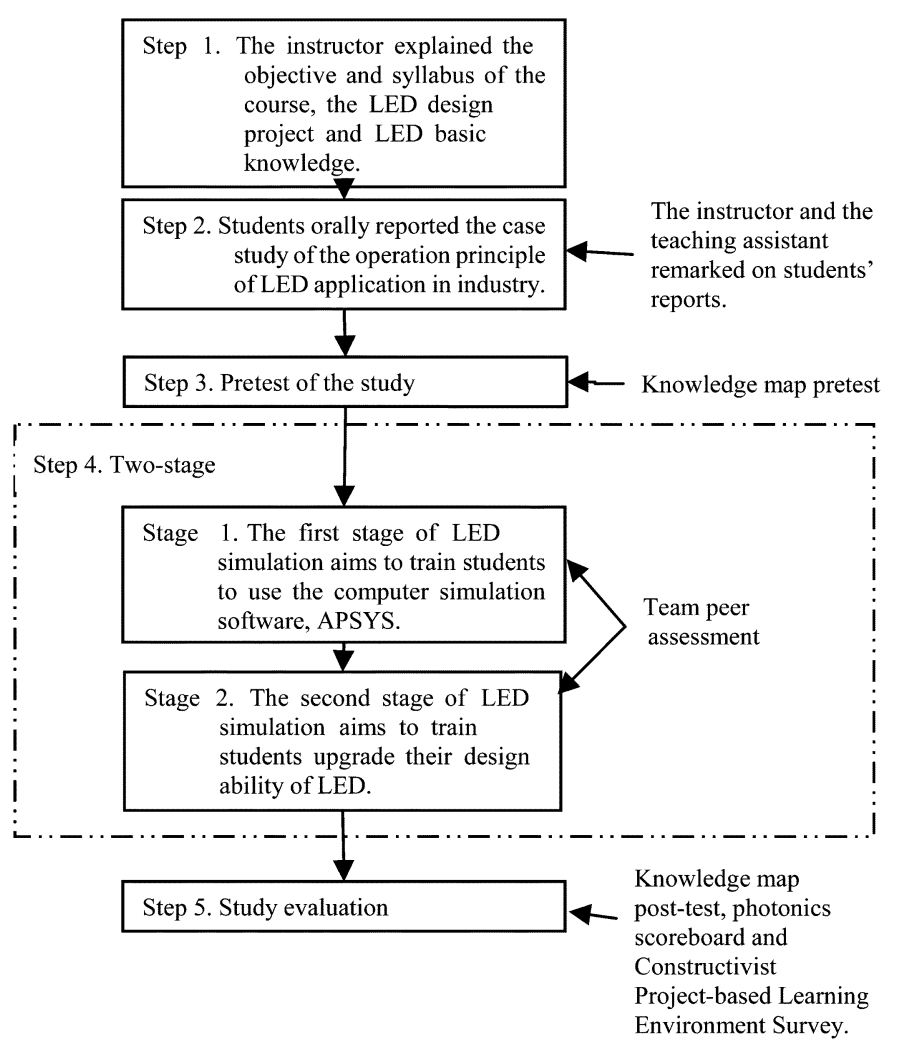

Fig. 2. Procedure of the project-based course.

simulation aims to train students to use the computer simulation software APSYS. The second stage of LED simulation aims to train students to improve their ability to design an LED. Each group was requested to design an LED. If the performance of the device did not meet the given specifications, then the teammates should correct either the parameters or the structure of the LED to reach or be closer to the project specifications. During these steps, teammates engaged in discussions and exchanged information and experience to clarify their concepts. Moreover, with the team online PA, each team was able to review the other three teams' projects and give review comments. Therefore, each team received review comments from three teams to help clarify their concepts and correct the parameters of their LED.

Step 5) The final step was the PBL evaluation, involving the knowledge map post-test, the photonics scoreboard, and the CPLES.

\section{LED SimULATION PROJECT}

Fig. 3 illustrates the two-stage simulation process for the LED. First, the instructor assigned a project to all the teams. Second, the students discussed this between themselves and researched information online and in textbooks or technical journals to form their initial ideas. Third, students performed simulations to clarify their concepts and ideas. In this step, the instructor and the teaching assistant taught students how to operate the simulation software to help them resolve any

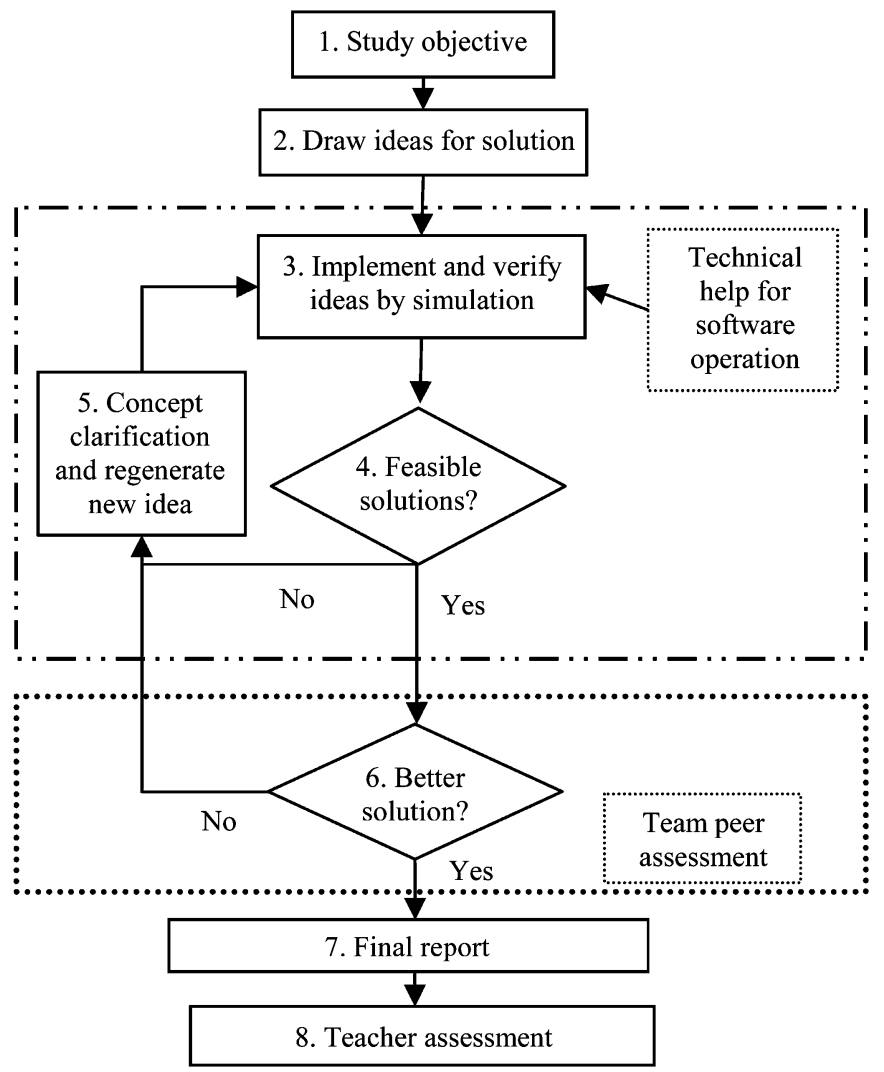

Fig. 3. Process of simulation-based learning with peer assessment.

operational difficulties. The teammates were expected to produce a solution to their set project following the simulation. In the fourth step, students checked if their solutions met the aim of the project. Students who had met the objective at this stage finished the simulation. Students who had not achieved the project goal were required to repeat steps 3-5. Repeating steps 3-5 helps students to build their concepts of the operating principle of LEDs. In the sixth step, all teams compared their results when they had achieved the objective. The team online PA step enabled the students to examine each others' results to understand how to gain better results by using different parameters.

APSYS, developed by the Crosslight Software, Inc., Burnaby, BC. Canada, was adopted in the project-based instruction. APSYS can be used to simulate several semiconductor devices, including LEDs, organic light-emitting diodes (OLEDs), photo-detectors, solar cells, electro-absorption modulators, high-electron mobility transistors, heterojunction bipolar transistors, metal-oxide-semiconductor field effect transistors, resonant tunneling diodes, and traveling wave semiconductor optical amplifiers. Fig. 4 shows the APSYS interface.

Fig. 5 displays the two simulation stages in this project-based instruction. In the first stage, the students were asked to design an InGaN blue LED with a wavelength of $450-480 \mathrm{~nm}$. The aim of this stage was to help students to learn how to operate APSYS and to realize how the different parameters influence the performance of an LED. In the second stage, students were asked to adjust the parameters to achieve an optimal LED performance with a given wavelength, current, and power. The objective of 


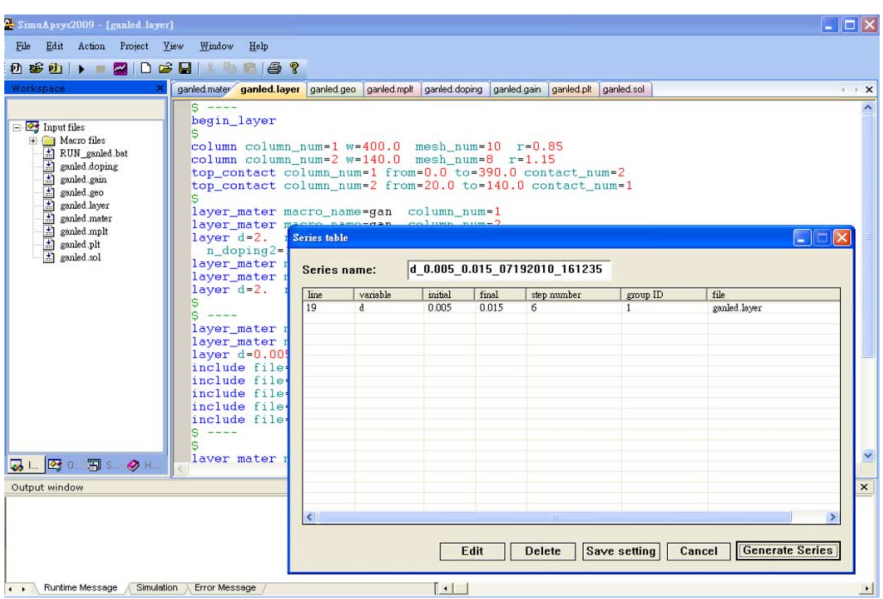

Fig. 4. APSYS interface.

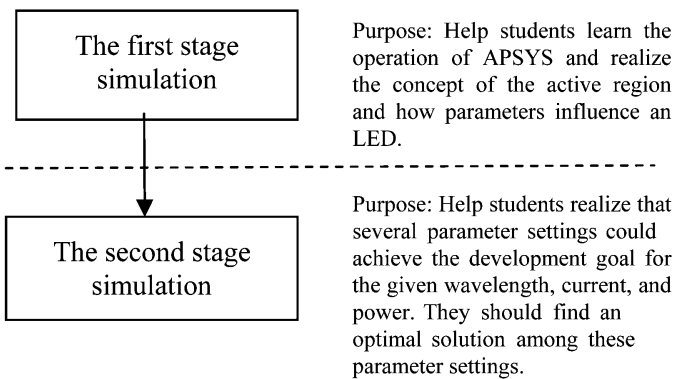

Fig. 5. Purposes of each simulation stage.

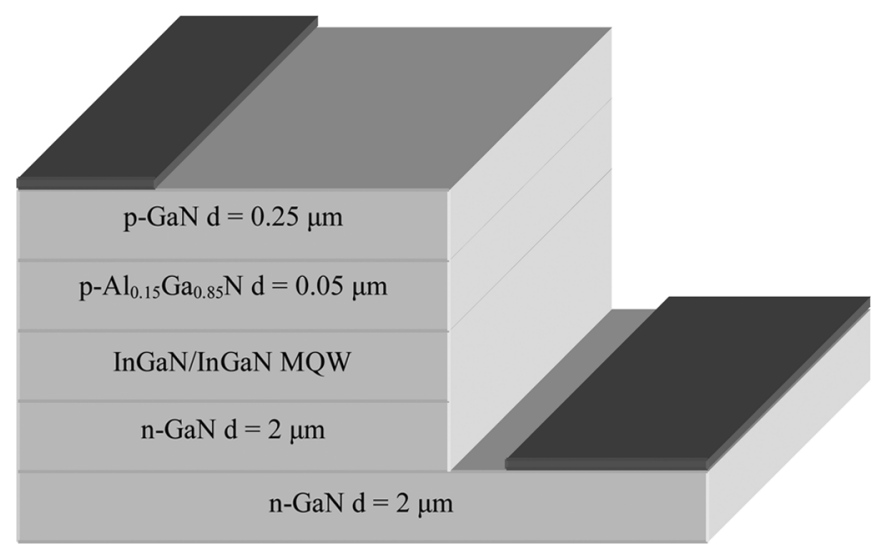

Fig. 6. Structure of a blue LED.

this stage was to help students understand that several parameters need to be adjusted to satisfy the wavelength, current, and power requirements and that an optimal solution would yield the correct settings.

Fig. 6 shows the structure of a blue LED used in this study. Students were required to adjust the InGaN well layer, the Shockley-Read-Hall (SRH) lifetime, and the internal loss in order to learn how these parameters influence the performance of the LED. For instance, increasing the indium (In) composition in the InGaN well layer lengthens the wavelength; decreasing the thickness of the InGaN well layer shortens the wavelength; reducing the internal loss can raise the output power and internal quantum efficiency.
TABLE I

DESCRIPTION OF STUDY EVALUATION TOOLS

\begin{tabular}{lll}
\hline $\begin{array}{l}\text { Objective of } \\
\text { evaluation }\end{array}$ & Evaluation tool & Description \\
\hline Knowledge & Knowledge map & $\begin{array}{l}\text { To examine student' concepts of } \\
\text { LED design after the project }\end{array}$ \\
\hline Skills & $\begin{array}{l}\text { Photonics } \\
\text { Scoreboard }\end{array}$ & $\begin{array}{l}\text { To evaluate the LED design skill by } \\
\text { expert assessment scores }\end{array}$ \\
\hline \multirow{3}{*}{ Attitude } & $\begin{array}{l}\text { Constructivist } \\
\text { Project-based } \\
\text { Learning }\end{array}$ & $\begin{array}{l}\text { To examine students' attitudes } \\
\text { toward the project-based learning } \\
\text { Environment } \\
\text { Survey (CPLES) } \\
\text { and in-depth } \\
\text { interview }\end{array}$ \\
& & \\
\hline
\end{tabular}

The second simulation stage had two objectives. The first was to design an LED with a wavelength of $460 \mathrm{~nm}$, an injection current of $30 \mathrm{~mA}$, and an output power of $1.5 \mathrm{~mW}$, according to the study of Oder et al. [32]. The other objective was to design an LED with a wavelength of $476 \mathrm{~nm}$, an injection current of $35 \mathrm{~mA}$, and an output power of $1 \mathrm{~mW}$, after the paper of Choi et al. [33]. In this stage, students attempted to reach the given targets based on the concepts that were established in the first stage.

\section{Study Evaluation}

The subjects of this project-based instruction were 69 junior students of the Department of Physics, National Changhua University of Education, Taiwan. The students were divided into 25 teams of two or three students. As mentioned, the study evaluation tools in this instruction were knowledge maps, a photonics scoreboard, and the CPLES, listed in Table I.

The pre- and post-test knowledge maps were applied to help evaluate the students' understanding of the principles of LED operation after the simulation. The photonics scoreboard, built on an Internet platform, was adopted for peer and expert assessment. The CPLES was developed to investigate the students' attitude toward the PBL environment [31]. In analyses of the reliability and of the exploratory factor of the CPLES, the Cronbach $\alpha$ for the whole instrument is over 0.95 , and the amount of explained variance is over $62 \%$ for each field test, figures that are high enough to demonstrate that CPLES can be applied to assess the students' attitude [31]. Discussion of the evaluation results follows.

\section{A. Knowledge Map}

A knowledge map is a two-dimensional figure that displays knowledge construction by nodes and lines [34]. A node denotes a key concept, and a line represents the relationship between two nodes. In the project-based instruction procedure, students were required to present their concepts of the LED via a knowledge map both before and after the simulation to examine whether the simulation helped them improve their understanding of the concepts of the LED. An expert in the Department of Physics, National Changhua University of Education, graded the students' knowledge maps based on the linkages between concepts. An 


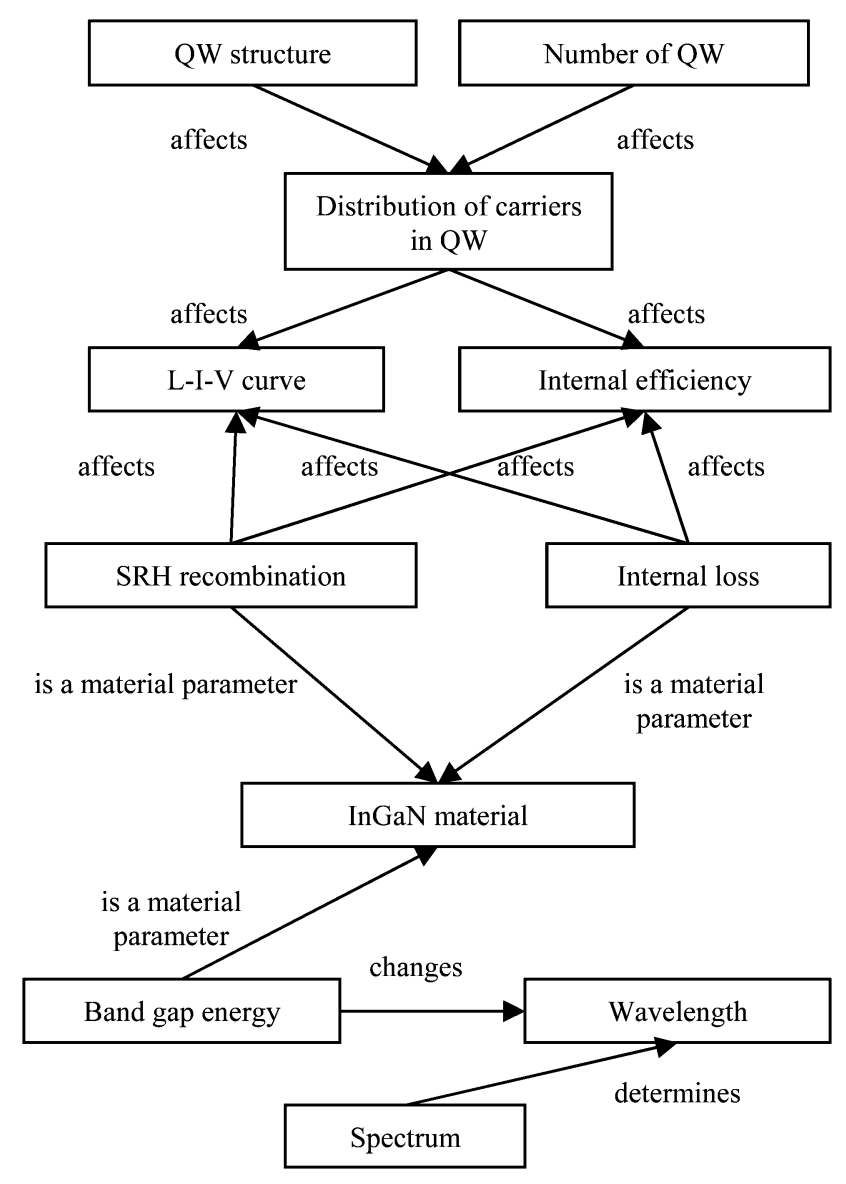

Fig. 7. Knowledge map example of the LED simulation.

TABLE II

$t$-Test of THE PRE- ANd Post-Test KNowledge Maps

\begin{tabular}{lcccc}
\hline & $\begin{array}{c}\text { Sample } \\
\text { Size }\end{array}$ & Mean & $\begin{array}{c}\text { Standard } \\
\text { Deviation }\end{array}$ & $\mathrm{t}$ \\
\hline Knowledge map pretest & 69 & 2.88 & 1.52 & \\
\hline Knowledge map post-test & 69 & 5.18 & 1.29 & \\
\hline$* p<0.05$ & & & & \\
\hline
\end{tabular}

incorrect proposition scored zero points, and a correct proposition scored 1 point. Fig. 7 presents an example of a map of the LED simulation.

Table II lists the $t$-test results of the pre- and post-test knowledge maps. The scores of the post-test knowledge map are significantly higher than those of the pretest. Comments by students included, "This is a difficult project. However, after this project, we can almost understand the operating principle of LEDs." Some students were able to clarify the concept of LED simulation after the instruction: "First, we should identify the range of parameters. Second, try to adjust the In composition in InGaN well layer. Then, change the number of quantum wells with the fixed SRH lifetime and internal loss. Finally, change the SRH lifetime with the fixed number of quantum wells and internal loss." These student comments indicate that this project helps students understand the basic knowledge behind, and operating principles of, LEDs.

\section{B. Photonics Scoreboard}

The photonics scoreboard had five rating items: the accuracy of device structure, originality, parameter adequacy, device performance, and device applicability. Each item was scored on a scale of 1-6 points. Thus, the maximum score was 30 points, and the lowest was 5 points.

The most important objective of this scoring system was to support open-ended suggestions by allowing students to give their opinions of other groups' outcomes, enabling concepts to be changed. Each team was required to review and assess the results of the other three teams, including the emission spectra, current-voltage $(I-V)$ curves, light-current $(L-I)$ curves, and efficiency curves, as well as the (.layer) and (.sol) files of APSYS that recorded the parameters. Fig. 8 shows the emission spectra, $I-V$ curve, $L-I$ curve, and efficiency curve achieved by one team when simulating LEDs with a wavelength of $476 \mathrm{~nm}$. These curves indicate that the team achieved the requirement of the second stage simulation with an injection current of $35 \mathrm{~mA}$ and an output power of $1 \mathrm{~mW}$.

Furthermore, the expert assessment scores given by the teacher were used to evaluate the students' LED design skills. A paired $t$-test was applied to these expert assessment scores before and after the introduction of PA, as shown in Table III, which reveals that these before and after scores were significantly different $(t=-8.966, p<0.001)$, with the expert assessment scores after PA (Mean $=22.00$ ) being higher than those before (Mean $=20.03)$. Thus, it can be concluded that the proposed learning course with online PA improved the students' LED design skills.

"Team online PA" attempts to provide teams with reference resources that they can use to correct their own parameters by allowing them to inspect the other teams' results and feedback. Team online PA instructs students to learn actively, be responsible, and think reflectively. Student comments on team online PA were collected in in-depth end-of-semester interviews with each team. The positive comments include, "Before the second stage simulation, we evaluated the other teams' results. According to our results, one team had the best power, so we emulated them to perform our second stage simulation," and "We found another team had some wrong results which were similar to results we had had in the process of searching for the optimal solution. We were happy to know that we could help them to correct the answers." This finding indicates that the team online PA aspect of this PBL course encourages students to understand where they could improve and to set themselves more challenging study goals.

\section{Constructivist Project-Based Learning Environment Survey}

After the project-based instruction, students were surveyed with the CPLES, a 5-point Likert-scale questionnaire ( $1=$ strongly disagree, $5=$ strongly agree) with five or six questions on inquiry learning, reflective thinking, teamwork, creative problem solving, open-endedness, and authenticity, respectively [31]. The inquiry learning subscale measures the opportunities of students to engage and explore. The reflective thinking subscale measures the opportunities for students to reflect on the process of their learning and thinking. The teamwork subscale measures the opportunities for students 


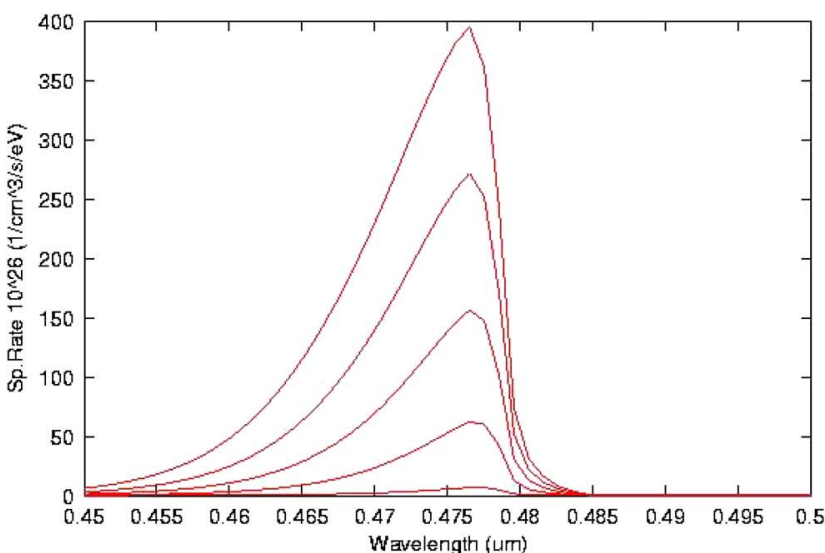

(a)

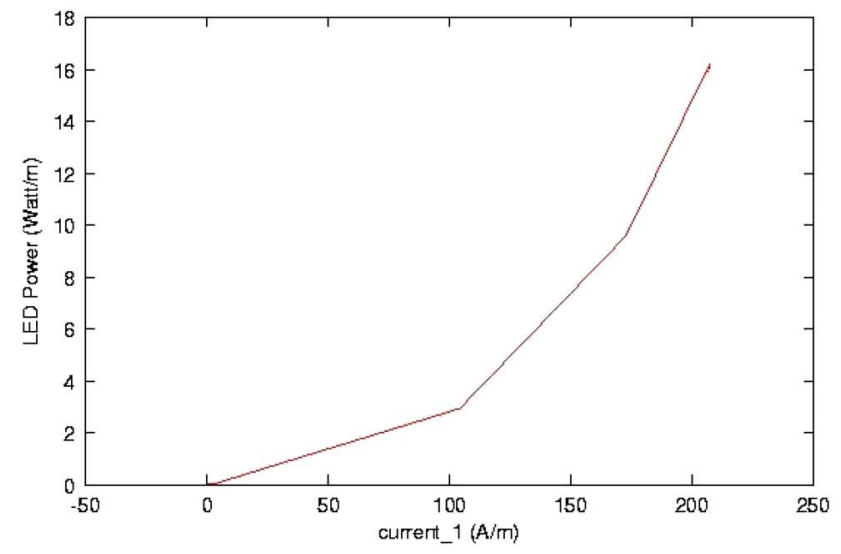

(c)

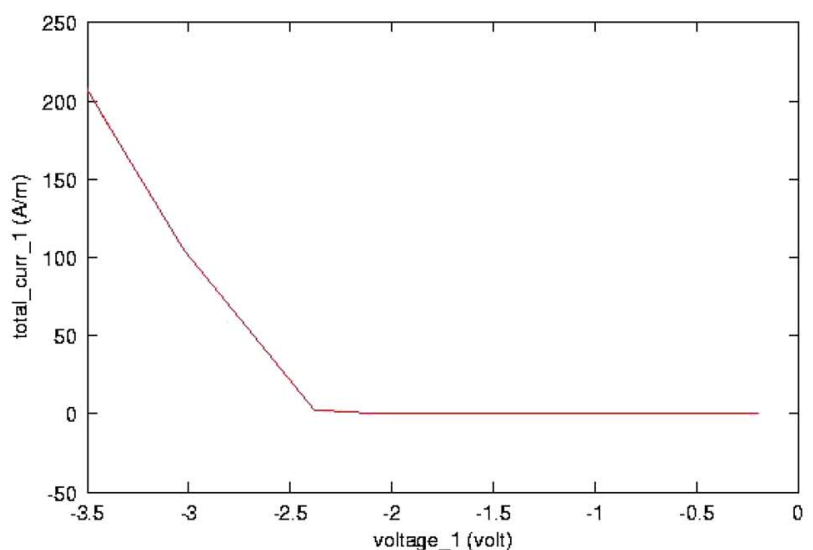

(b)

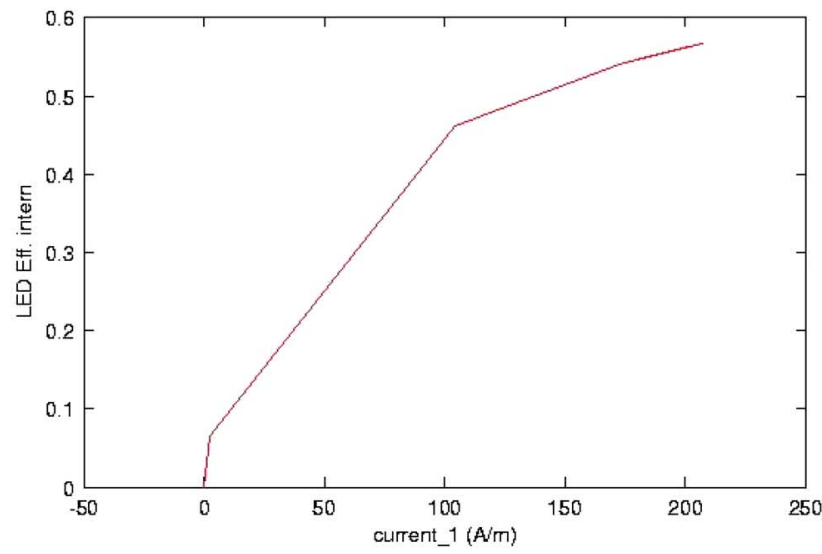

(d)

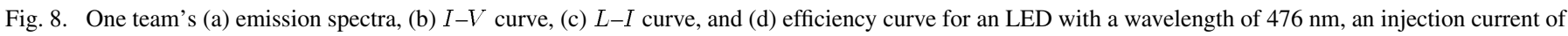
$35 \mathrm{~mA}$, and an output power of $1 \mathrm{~mW}$ in the second stage simulation.

TABLE III

$t$-TEST OF EXPERT ASSESSMENT SCORES BEFORE AND AFTER PA

\begin{tabular}{lcccc}
\hline & $\begin{array}{c}\text { Sample } \\
\text { Size }\end{array}$ & Mean & $\begin{array}{c}\text { Standard } \\
\text { Deviation }\end{array}$ & $\mathrm{t}$ \\
\hline $\begin{array}{c}\text { Scores of expert } \\
\text { assessment before PA }\end{array}$ & 25 & 20.03 & 1.32 & \\
\cline { 1 - 1 } & & & & \\
$\begin{array}{c}\text { Scores of expert } \\
\text { assessment after PA }\end{array}$ & 25 & 22.00 & $0.94 * *$ & \\
${ }^{* *} p<0.001$ & & & & \\
& & & &
\end{tabular}

to work as a team and learn skills including adaptability, communication, coordination, decision making, interpersonal relationships, and leadership. The creative problem-solving subscale measures the opportunities for students to solve problems creatively. The open-endedness subscale measures the open-endedness and diversity of approaches used in the study. The authenticity subscale measures the realism and authenticity of the problems set in the project. The average scores for each of these subscales are listed in Table IV, and in each case were greater than or equal to 3.5 .

These results reveal that the proposed course of this study helps students to be more reflective and curious in their thinking and in their learning process, to develop teamwork skills, and thus to solve problems more creatively. The proposed course also had the features of open-endedness, diversity, and authenticity. Student comments included, "We learned the structure of an LED and the operation of computer simulation software. Collaboration by teammates is important. We discussed enthusiastically between ourselves when experimenting. After the class, we discussed how to improve what we'd done. Every teammate wanted to do it perfectly."

\section{Discussion AND CONCLUSION}

Based on industry-university collaboration in Taiwan, which has been adopted to cope with the time-consuming and expensive development process of optical semiconductor devices, this study develops a novel instructional approach — an SBL course with online PA to develop students' professional skills in LED design as required by industry and to enhance the cognitive and metacognitive outcomes of students in higher education. The overall results of an evaluation by knowledge maps, a photonics scoreboard, and the CPLES reveal that the proposed projectbased instruction can fulfill the aforementioned seven goals of constructivist learning environments.

The results of the pre- and post-test knowledge maps and the photonics scoreboard indicate that this SBL helps students understand the operating principle of LEDs. Moreover, this project-based instruction fosters the ability to design LEDs, to perform experiments, to analyze and interpret data, to communicate effectively, and to recognize the necessity of lifelong 
TABLE IV

Average SCORES For Each SubsCALE OF the ProJect-Based Learning ENVIRONMENT SURVEY

Score

Mean

Questions for each subscale

Deviation)

Upon completion of the project-based learning course, please answer the following questions.

Inquiry learning subscale - I had the opportunity to:

1. Conduct research to find the answers to questions.

2. Conduct research to verify my ideas.

$(0.52)$

3. Proceed with further research to solve new problems.

4. Design/develop research methods by myself.

5. Collect data, analyze data and present the report.

Reflective learning subscale - I had the opportunity to:

1. Reflect on how I learn things.

2. Deliberate upon my thoughts in detail.

3. Learn how to become a better learner.

4. Present my areas of uncertainty.

5. Criticize my own research results.

Teamwork subscale- I had the opportunity to:

1. Use the information provided by group members to solve problems.

2. Contribute to the group goals.

3. Help other group members with their work.

4. Be a leader to teach other group members.

5. Exchange and share information or opinions with other students.

AND

6. I loved working with my teammates.

Creative problem solving subscale - I had the opportunity

to:

1. Detect errors and confirm that they were properly corrected.

2. Propose my own creative ideas.

3. Apply my creative ideas into designs or assigned tasks.

4. Evaluate all the possible solutions to problems.

Open-endedness subscale- The teacher let us:

1. Design methods for problem-solving by ourselves.

2. Present our own project proposals.

3. Use various types of data to solve the same problem in different ways.

4. Study the particular problems of our own that interested us.

5. Decide how to proceed with our project.

6. Solve problems from various perspectives.

Authenticity subscale

1. The problems met in this project indicate the complexity of practical problems.

2. The information presented in this project is relevant to authentic real-world problems.

3. The knowledge and experience provided by this project are relevant to authentic real-world problems.

. The problems in this project are derived from practical problems in authentic real-world tasks.

5. Upon the completion of this project, I fully understood its objective and the subject matter.

learning, which is similar to the results of the studies of Lunette and Hofstein [13], Stern et al. [12], and Lehmann et al. [6].

However, the results of this study indicate that the LED designs generated by the simulation system need to be further verified by someone with more practical knowledge and experience, such as the teacher or teaching assistant. Therefore, future studies of SBL need to discuss how to equip students with the ability to verify the outcome of their design work and the reasonable intervals for the parameters.

In terms of the effectiveness of team online PA, the in-depth interviews with each team indicate that it encourages students to understand where they could improve and to set higher goals for themselves. Similar to the viewpoints of Topping [28] and Wen and Tsai [35], the results of the study show that through online PA students can observe how their peers think and learn. Team online PA helps students conduct self-reflective thinking and clarify their misconceptions. However, the possibility of plagiarism and the overhead time needed to train students for PA might be perceived to be a concern [36].

The CPLES was used to demonstrate that the proposed learning methodology, combined with an open-ended and authentic leaning environment, can cultivate students' inquiry learning, reflective thinking, teamwork, and creative problem-solving skills. However, the strategies and arrangements for group-discussion problem solving and for online PA can influence the effects of learning [36]-[40]. Future studies might focus on different strategies and arrangements for group-discussion problem solving and online PA in order to investigate these PBL effects.

\section{ACKNOWLEDGMENT}

Special thanks are extended to research team members S.-H. Yen, J.-R. Chen, C.-H. Yang, and Y.-H. Huang of the Institute of Photonics and C.-M. Lee and Y.-L. Yang of the Department of Industrial Education and Technology, National Changhua University of Education, Taiwan. The authors also wish to express appreciation to T. Knoy, a native English speaker, for his editorial assistance.

\section{REFERENCES}

[1] H. Y. Huang, Opto-Electronics Industry Yearbook. Taipei, Taiwan: Industrial Economics and Knowledge Center, Industrial Technology Research Institute, 2006.

[2] J. Huang, "Taiwan's solar-optoelectronics and LED industries forecast to hit NT\$1 trillion production value by 2015," LEDinside Dec. 2009 [Online]. Available: http://www.ledinside.com.tw/ news_2015_LED_20091105

[3] Y. K. Kuo, "Simulation analysis and design for high-efficient lightemitting diodes and solar cells," Research Project of EpiStar Inc. and National Changhua University of Education, Changhua, Taiwan, Final Rep. NSC 97-2815-C-018-003-M, 2008.

[4] J. Macías-Guarasa, J. Montero, J. M. San-Segundo, R. Araujo, and O. Nieto-Taladriz, "A project-based learning approach to design electronic systems curricula," IEEE Trans. Educ., vol. 49, no. 3, pp. 389-397, Aug. 2006.

[5] M. J. Prince and R. M. Felder, "Inductive teaching and learning methods: Definitions, comparisons, and research bases," J. Eng. Educ., vol. 95, no. 2, pp. 123-138, Apr. 2006.

[6] M. Lehmann, P. Christensen, X. Du, and M. Thrane, "Problem-oriented and project-based learning (POPBL) as an innovative learning strategy for sustainable development in engineering education," Eur. J. Eng. Educ., vol. 33, no. 3, pp. 283-295, Jun. 2008.

[7] B. F. Jones, C. M. Rasmussen, and M. C. Moffitt, Real-Life Problem Solving: A Collaborative Approach to Interdisciplinary Learning. Washington, DC: APA, 1999. 
[8] J. W. Thomas, J. R. Mergendoller, and A. Michaelson, Project-Based Learning: A Handbook for Middle and High School Teachers. Novato, CA: Buck Inst. Educ., 1999.

[9] C. E. Hmelo and X. Lin, "Becoming self-directed learners: Strategy development in problem-based learning," in Problem-Based Learning: A Research Perspective on Learning Interactions, D. H. Evensen, H. Dand, and C. E. Hmelo, Eds. Mahwah, NJ: Erlbaum, 2000, pp. 227-250.

[10] R. San-Segundo, J. M. Montero, J. Macías-Guarasa, J. Ferreiros, and R. Córdoba, "Towards the acquisition of soft and systemic skills: A project based learning experience in massive laboratories on electronics," presented at the ICECE, Madrid, Spain, 2005.

[11] D. L. Maskell and P. J. Grabau, "A multidisciplinary cooperative problem-based learning approach to embedded systems design," IEEE Trans. Educ., vol. 41, no. 2, pp. 101-103, May 1998.

[12] F. Stern, X. Tao, D. B. Yarbrough, A. Rothmayer, G. Rajagopalan, S. P. Otta, D. Caughey, R. Bhaskaran, Smith, B. Hutchings, and S. Moeykens, "Hands-on CFD educational interface for engineering courses and laboratories," J. Eng. Educ., vol. 95, no. 1, pp. 63-83, Jan. 2006.

[13] V. Lunette and A. Hofstein, "Simulation and laboratory practical activity," in Practical Science, B. Woodnough, Ed. Milton Keynes, U.K.: Open Univ. Press, 1991.

[14] A. M. Castro, C. M. Mediano, and E. L. Aldea, "Work in progress-Integration of new tools and technologies in electronics teaching," presented at the 34th ASEE/IEEE Frontiers in Educ. Conf., Savannah, GA, Oct. 20-23, 2004, Paper T1C 10.

[15] A. Emadi and T. M. Jacobius, "Interprofessional projects in advanced automotive power systems: An integrated education and research multidisciplinary approach," IEEE Trans. Educ., vol. 47, no. 3, pp. 356-360, Aug. 2004.

[16] S. Ayasun and C. O. Nwankpa, "Induction motor tests using MATLAB/ Simulink and their integration into undergraduate electric machinery courses," IEEE Trans. Educ., vol. 48, no. 1, pp. 37-46, Feb. 2005.

[17] G. W. Chang, Z. M. Yeh, Y. H. Lin, and H. M. Chang, "A grating-based spectral filtering project in photonics instrumentation," IEEE Trans. Educ., vol. 49, no. 1, pp. 166-175, Feb. 2006.

[18] M. G. Marasinghe, W. Q. Meeker, D. Cook, and T. Shin, "Using graphics and simulation to teach statistical concepts," Amer. Statistician, vol. 50, pp. 342-351, Nov. 1996.

[19] J. D. Mills, "Learning abstract statistics concepts using simulation," Educ. Res. Quart., vol. 28, no. 3, pp. 18-33, 2005.

[20] L. P. Rieber and M. W. Parmley, "To teach or not to teach? Comparing the use of computer-based simulations in deductive versus inductive approaches to learning with adults in science," J. Educ. Comput. Res., vol. 13 , pp. 359-374, 1995 .

[21] B. G. Wilson, "Constructivist learning environments: case studies in instructional design," in Constructivist Learning Environments, B. G. Wilson, Ed. Englewood Cliffs, NJ: Educational Technology, 1996, pp. 3-8.

[22] D. N. Perkins, "The many faces of constructivism," Educ. Leadership, vol. 57, no. 3, pp. 6-11, Nov. 1999.

[23] C. C. Tsai, "Science learning and constructivism," Curriculum Teach., vol. 13, pp. 31-52, 1998.

[24] C. C. Tsai, "Relationships between student scientific epistemological beliefs and perceptions of constructivist learning environment," Educ. Res., vol. 42, no. 2, pp. 193-205, Jul. 2000.

[25] M. L. Wen, C. C. Tasi, H. M. Lin, and S. C. Chuang, "Cognitivemetacognitive and content-technical aspects of constructivist Internetbased learning environments: A LISREL analysis," Comput. Educ., vol. 43, no. 3, pp. 237-248, Nov. 2004.

[26] D. Cunningham, T. M. Duffy, and R. Knuth, "Textbook of the future," in Hypertext: A Psychological Perspective, C. Mcknight, Ed. London, U.K.: Ellis Horwood, 1993.

[27] P. C. Honebein, "Seven goals for the design of constructivist learning environments," in Constructivist Learning Environments, B. G. Wilson, Ed. Englewood Cliffs, NJ: Educational Technology, 1996, pp. 11-24.

[28] K. J. Topping, "Peer assessment between students in colleges and universities," Rev. Educ. Res., vol. 68, no. 3, pp. 249-276, 1998

[29] P. Davies, "Computerized peer assessment," Innov. Educ. Teach. Int., vol. 37, no. 4, pp. 346-354, Nov. 2000.

[30] C. C. Liu and C. M. Tsai, "Peer assessment through Web-based knowledge acquisition: Tools to support conceptual awareness," Innov. Educ. Teach. Int., vol. 42, no. 1, pp. 43-59, Feb. 2005.

[31] S. H. Chang, "Enhancing the skills of photonics device design through the project-based course development and evaluation," National Science Council, Taipei, Taiwan, Final Rep. NSC 95-2516-S-018-001MY3, 2006.
[32] T. N. Oder, K. H. Kim, J. Y. Lin, and H. X. Jiang, "III-nitride blue and ultraviolet photonic crystal light emitting diodes," Appl. Phys. Lett., vol. 84, no. 4, pp. 466-469, Jan. 2004.

[33] R. J. Choi, Y. B. Hahn, H. W. Shim, M. S. Han, E. K. Suh, and H. J. Lee, "Efficient blue light-emitting diodes with InGaN/GaN triangular shaped multiple quantum wells," Appl. Phys. Lett., vol. 82, no. 17, pp. 2764-2766, Apr. 2003.

[34] E. C. McCagg and D. F. Dansereau, "A convergent paradigm for examining knowledge mapping as a learning strategy," J. Educ. Res., vol. 84, no. 6, pp. 317-324, 1991.

[35] M. L. Wen and C. C. Tsai, "University students' perceptions of and attitudes toward (online) peer assessment," Higher Educ., vol. 51, no. 1, pp. 27-44, Aug. 2006.

[36] V. Garousi, "Applying peer reviews in software engineering education: An experiment and lessons learned," IEEE Trans. Educ., vol. 53, no. 2, pp. 182-193, May 2010.

[37] F. Sen and W. G. Engelhoff, "Innovative capabilities of a firm and the use of technical alliances," IEEE Trans. Eng. Manag., vol. 47, no. 2, pp. 174-183, May 2000

[38] G. Hirst and L. A. Mann, "A model of R\&D leadership and team communication: The relationship with project performance," $R \& D$ Manag. vol. 34, no. 2, pp. 147-160, Mar. 2004.

[39] K. A. Smith, S. D. Sheppard, D. W. Johnson, and R. T. Johnson, "Pedagogies of engagement: Classroom-based practices," J. Eng. Educ., pp. 1-15, Jan. 2005.

[40] Y. C. Chen and C. C. Tsai, "An educational research course facilitated by online peer assessment," Innov. Educ. Teach. Int., vol. 46, no. 1, pp. 105-117, Feb. 2009.

Shu-Hsuan Chang received the B.S. and M.S. degrees in industrial engineering from National Chiao-Tung University, Taiwan, in 1989 and 1991, respectively, and the $\mathrm{Ph} . \mathrm{D}$. degree in industrial education and technology, National Changhua University of Education (NCUE), Taiwan, in 1998.

In 2003, she joined the faculty of the Department of Industrial Education and Technology, NCUE. She joined the Laboratory of Lasers and Optical Semiconductors, NCUE, in 2005, where she engaged in research on optical semiconductor devices and their applications. Currently, she is a Professor with NCUE. Her recent research interests include light-emitting diodes, organic light-emitting diodes, engineering education, and management of technology.

Mei-Ling Chen received the M.S. degreein science in teaching from the University of Wisconsin, River Falls, in 1992.

She became an Instructor with the Physics Department, National Changhua University of Education (NCUE), Taiwan, in 1993. She then joined the Laboratory of Lasers and Optical Semiconductors, NCUE, where she engaged in research on optical semiconductor devices simulations. Her recent research interests include simulation of laser diodes and LEDs.

Yen-Kuang Kuo received the B.S. degree in electrophysics from National Chiao-Tung University, Taiwan, in 1982, the M.S. degree in electrical engineering from National Taiwan University, Taiwan, in 1984, and the Ph.D. degree in electrical engineering from the University of Southern California (USC), Los Angeles, in 1994.

In 1997, he joined the faculty of the Department of Physics, National Changhua University of Education (NCUE), Taiwan, where he is a Professor with the Department of Physics and Institute of Photonics and the Head of the Laboratory of Lasers and Optical Semiconductors. In 2008, he was elected to be the Dean of the College of Science, NCUE. He has published several papers in the fields of solid-state lasers and optical semiconductor devices. His recent research interests include numerical simulation of semiconductor lasers, light-emitting diodes, organic light-emitting diodes, and solar cells.

Yung-Chi Shen received the B.S. degree in international business studies from National Chi Nan University, Taiwan, in 2005, the M.S. degree industrial education and technology, National Changhua University of Education, Taiwan, in 2007, and the Ph.D. degree in technology management from National ChiaoTung University, Taiwan, in 2010.

His areas of research are in technology management, patent analysis, and national innovation policy, and he recently published an academic paper in entrepreneurship and regional development. 